the human kind. His Traité des Dégénérescences Humanes is an original work, the reputation of which will grow with the growth of our knowledge; for in it he has marked the lines which futare researches must follow in a most promising and im. portant feld of enquiry. His Traite des Maladies Mentales is a standard work, and, philosophical in its scope, full of valuable observation, profoundly suggestive, and oparkling with gleams of original insight. Nowhere else will so complete and exact an account be found of the characters of the varieties of hereditary insanity, nor so account be found oftion chracters oientific point of view, of the ontire cansation of complete an exposition, from a scientific point of view, of the entire causation of
insanity. The etiological system of classification which he has proponnded should be well. innown to our readers. Though it has not been adopted as a practical system of classification, there are features in it of which assuredly account will have to be taken in the formation of a complete classification, when the time comes for it. Besides these standard treatises Morel published a work on the Medical Jurispradence of Insanity, and many most important contributions at different times on medico-legal cases, and on other matters of medico-psychological research. Among these wo may specify, as being of eppecial excellence, his work De la Formation du these wo may specify, as being of epecial excellence, his work De la Formation du Type dans les Varietes Degenerres, 1864 , a medico-legal report De la Folie Hereditaire,
1864 , and a valuable contribation D'une forme de Delire suite d' une surexcitation nerveuse se rattachant d une variete non encore decrit d'Epilepsie-Epilepsie Larvee. His medico-legal reports on different cases which he was culled upon to examine are to be found in the pages of the Annales Medico-psychologiques, and will well repay the study which they deserve. One of his last appearances as an expert was in the affair Chorinsky, of which we give a brief notico in this Journal, and it is a striking proof of his thorough competence, and of the confidence which a complete and exact knowledge begets, that on that occasion he predicted that Chorinsky would die of paralysis or epilepey, and that the man has since died of paralysis.

Morel was not honoured with much worldly honour or recompense in France. His life was spent as the physician of a provincial asylum. He had fallen on the evil days of Imperialism, and he was of too noble and sincere a nature to follow in the train of its supporters; he could not frame his lips to speak well of him who, having most solemnly sworn, as President of the Republic, to preserve the Republic, inmediately afterwards, aided by a band of congenial conspirators, strangled liberty in the night, and consecrated its destruction by the murder and transportation of its martyrs. But he has left behind him a name which will be remembered so long as men shall study the history of the origin and development of medico-psychology and should the time come, as no doubt it will come, when his name is no longer beard of, when his individual reputation, like his bodily individuality, shall have passed away, the original and useful work which he has done will not perish; it passed away, the original and nseful work which he has done will not perish; which, it may be presumed, will go on in the time to coure as it has gone on in the time past.

\title{
THOMAS POWER, M.D.
}

The demise of another of the resident Medical Superintendents in Ireland has unhappily to be again recorded, following comparatively soon that of Dr. Smith of Londonderry. In the present instance, an experienced and worthy member of the specialty, in the person of Thomas Power, M.D., of the Cork District Hospital for the Insane has to be announced, he having succumbed, on the 17th April last, more immediately to an attack of bronchitis complicated with Emphysema and a more immediately to an attack of bronchitis complicated with Emphysema and a gouty diathesis. He had attained the ripe age of 72 and up to the last few months
continued in the active performance of his onerous duties. A more kindly or well. continued in the active perfurmance of his onerous daties. A more kindly or well. lose been felt by the inmates of his Institution, in whose charge it had been for the lengthened and trying period of 28 years, his appointment dating in 1845 . Dr. Power had a highly oultivated mind, and was well and thoroughly educated in his profession, having after graduating as M D., in Edinburgh University, in 1823, profession, having, after graduating as $\mathrm{M}$ D., in Edinburgh eleres faenec, Velpeau, \&c. He, besides being Lecturer on Botany in the Cort School of Medicine, was the author of a nseful and interesting little volume entitled, "Flora of County Cork," also a "Report on first employment of Turkish Bath as s remedy in Insanity." Dr. Power was a widower for the last few years, and has left behind him sons and daughters to mourn his loss. His eldest son in the pro fession also holds a lucrative and important position in the Military Medical Department at Hong Kong. Another son likewise is a medical man. 